\title{
Organisation Design and Adaptability of the Organisation
}

\author{
Chief Ass. Prof. Vesselina Maximova, PhD \\ University of Economics - Varna, Varna, Bulgaria \\ v_maximova@ue-varna.bg
}

\begin{abstract}
The article builds upon the thesis that developing an adaptive organisation is strongly determined by the choice of organisational design. By reviewing design components and their importance for organisational adaptability, we outline the organisational features that design choice is to ensure for adaptability to be achieved. The benefits of using project organisational structure, adhocracy and networks in ensuring adaptability are discussed. Beside the requirements regarding "organisational hardware", arguments for the significance of softer organisational components are given. Results of our own and others' empirical studies on the role of soft organisational elements such as managerial philosophy, trust-and loyalty-based relationships with contracting parties and staff and aptitude to continuous innovation in building agility are also reported.
\end{abstract}

Keywords: organisation design, adaptability, project organisational structure, adhocracy, networks, soft organisational elements, organisations' agility

JEL Code: L200, L220, M100 DOI: https://doi.org/10.36997/IJUSV-ESS/2020.9.3.106

\section{Въведение}

В наши дни пред предизвикателството да работят и постигат резултати в сложна и динамична среда са изправени дори организации, които по- рано са възприемали индустрията, в която работят, като относително стабилна, с утвърдени пазари, слабо променяща се регулативна среда, относително защитена от навлизане на нови конкуренти. Намирането на подходящите и навременни решения, които да поставят организацията в съответствие с променящите се изисквания на средата, става от критично значение за нейния успех и е функция на способността й да се адаптира. Адаптивността се свързва както с ефективния отговор на променена ситуация, така и с проактивното планиране на поведението на организацията в случай на бъдещи промени в условията, при които работи (Boylan \&Turner, 2017). На ролята на организационното проектиране за постигането на съответствие с променящата се среда обрьщат внимание Грийнууд и Милър (2010) като настояват, че ,повечето от най- честите и изискващи спешни мерки предизвикателства могат да бъдат адресирани чрез непрекъснат и добре обмислен процес на изграждане на организационния дизайн“ (Greenwood \& Miller, 2010). Така дизайнът на организацията, или проектирането на нейните основни компоненти и връзките между тях, е сред основните предпоставки за развитието на адаптивни организации.

Вниманието ни в статията е насочено към извеждане на характеристики на организационния дизайн, които допринасят за адаптивността на организациите. След кратко представяне на понятието „адаптивност“ ще потьрсим отговор на въпросите: Кои елементи на организационния дизайн оказват влияние на адаптационните способности на организацията; какво отличава адаптивните организации от останалите? Интерес провокира и въпросът дали е възможно организацията да остане стабилна като в същото време се приспособява към различните условия на външната среда. Становището си по тези въпроси формираме, от една страна, чрез преглед на теоретични модели за организационен дизайн, представени накратко в доклада и, от друга страна, чрез търсене на емпирично потвърждение за връзката между някои организационни характеристики и продължаващото успешно представяне на компаниите в променяща се среда. Валидирането на тази връзка търсим както в наши емпирични изследвания, така и в публикувани емпирични резултати на други изследователи. 


\section{1. Дефиниране на адаптивността}

Думата „адаптирам“ е с латински произход, от „аdapto“- съчетавам. В български тълковен речник „адаптирам“ е обяснено като „нагаждам, приспособявам“, а в Collins English Dictionary сред синонимите на глагола „to adapt“ са посочени „to adjust, to match, to fit“. Tака, от етимологична гледна точка да адаптираш означава да приспособиш, да съчетаеш или да приведеш в съответствие към нещо (ситуация, обстоятелства, характеристики на друг обект). Адаптивността от своя страна е способността на системите (биологични, икономически, социални и пр.) да се приспособяват, да се привеждат в съответствие с други обекти, условия, обстоятелства.

В литературата, посветена на организациите, свойството „адаптивност“ често се обяснява или заменя с „гъвкавост“, „подвижност“ (agility), „способност за реакция“ (responsiveness). Признавайки, че в литературата не е възприета единна дефиниция за адаптивността, Бойлан и Търнър (2017) извеждат основни моменти в нейното дефиниране като се позовават на определението на Института за анализи в отбраната (Institute for Defense Analysis, IDA). Същият дефинира адаптивността като „степента, в която приспособяването на процедурите, процесите или структурите към проектираните или действителните промени в обкръжаващата среда е възможно“ и добавят, че „адаптирането може да е спонтанно или планирано и да се осъществява в отговор на или като очакване на промени в условията“

Можем да отличим няколко особености, които се съдържат в това определение:

1) адаптивността е необходима заради промени в средата;

2) адаптивността се свързва с поведение, което е реактивно, в отговор на вече проявили се промени, или проактивно и планирано, като подготовка за предвидени бъдещи промени;

3) адаптивността предполага извършване на промени в елементите на организационния дизайн (процедурите, процесите, структурите).

Последното прибавя аргументи за необходимостта от разглеждане на връзката между организационния дизайн и способността за адаптиране на организациите и от търсене на онези характеристики и елементи на дизайна, които са значими за постигането на адаптивност.

Пенчев и Петков (2014) дават определение за адаптивно предприятие, а именно: „адаптивно е това предприятие, което е в състояние да отговаря бързо и адекватно на сътресенията на външната, все по-турбулентна бизнес среда, да прогнозира новите световни бизнес тенденции и да използва кризисните моменти като нови възможности за развитие. То е в състояние да преодолява без сътресения внезапните вътрешни за него проблеми. Адаптивното предприятие използва всяка външна и вътрешна промяна в средата за повишаване на своята конкурентоспособност и по този начин подсигурява устойчиво във времето и печелившо съществуване“.

Предвид горното определение можем да отбележим още няколко характеристики на адаптивността:

4) тя се отнася освен за приспособяване към изменения, идващи от външната среда, така и за отговор на вътрешни за организацията проблеми;

5) адаптивността се характеризира и със скоростта на реакция на организациите на измененията в средата - адаптивна е онази организация, която е „в състояние бързо да отговаря“" на промените в средата;

6) адаптивността се свързва и с отношението към кризисните моменти, а именно с възприемането на последните като възможности за развитие от страна на мениджърите.

Позовавайки се и на други автори, Пенчев и Петков (2014) отбелязват, че „адаптивността е подход на организиране на предприятието, с който се постига бърза пренастройка на системите, за да се отговори на неочакваните промени“ (Bernardes \&Hanna, 
2009). Тази гледна точка поставя в центъра на адаптивността именно организирането, респ. избора и изграждането на организационния дизайн.

Становища на други автори също насочват към връзката между адаптивността и дизайна на организациите. Разглеждайки идеята за адаптивността с нейните две основни тези: „функционирането на системите (организациите) е непрекъснат процес на адаптация“ и „в еволюционен план оцелява по-адаптивният“, Калинов обобщава, че „еволюцията е адаптация“ (Kalinov, 2017). Еволюцията от своя страна и периодите, през които организациите преминават през своя жизнен цикъл, се характеризират със специфичен набор от основни избори, които организациите правят по отношение на своя дизайн. Всеки етап от развитието на организациите изисква нова съвкупност от избори за това какви да са приоритетите на ръководството, каква да е организационната структура, стилът на управление, системите за контрол, начина на определяне на възнагражденията - тези променливи включва в модела си за растеж на организациите Лари Грейнър, описвайки петте фази в развитието на организациите и дефинирайки проблемите, които закономерно се пораждат на всеки от тези етапи на развитие (Greiner, 1972).

В управленската наука (в частност в ситуационния подход) и в организационната теория широко приемане има тезата за съответствието, която обвързва успеха на организациите както със съответствието между компонентите, изграждащи дизайна на организацията (вътрешно съответствие), така и със съответствието между организацията и нейната среда (външно съответствие). Предвид начина, по който по- горе дефинирахме адаптивността, а именно със способността организациите да привеждат в съответствие, да приспособяват процесите и структурите си към различните измерения на средата, считаме за основателна тезата, че адаптивността на организациите е силно детерминирана от изборите, които техните мениджъри правят по отношение на дизайна им и че търсенето на теоретични и емпирични обосновки за това кои организационни решения са в полза на адаптивността остава актуално.

\section{2. Компонентите на организационния дизайн и приносьт им в осигуряване на адаптивност}

Различни модели за дизайн на организацията предлагат комплекс от организационни компоненти, чрез които да се опишат основните избори, които организациите правят на различни етапи от своето развитие. Тези модели включват както компоненти като организационна структура, система за вземане на решения, процеси, система за възнаграждения, механизми за контрол, възприемани като по- „твърди“ компоненти и често наричани „организационен хардуер“, така и „меки“ компоненти, които ведно с първите изграждат целостта на организацията. В табл. 1 в съпоставителен разрез са представени компонентите на организацията, които различни изследователи включват в моделите си за изучаване (диагностика) и/ или дизайн на организациите.

Организационният хардуер е този, който се поддава на формално описание, описанието му се материализира в организационни схеми, схеми от свързани процеси, писани процедури, инструкции, разпределящи правомощия и отговорности по вземане на решения, схеми на информационни потоци, системи от показатели, измерващи представянето и т.н. Проектирането на организационния хардуер се очаква да осигури стабилната база за относително дългосрочното функциониране на организацията.

Това, от което зависи как и доколко ще се използва потенциалът на „хардуера“, са компонентите, които изграждат т. нар. „организационен софтуер“. В него са включвани променливи като лидерство и взаимоотношения (6- компонентен модел на Weisbord), споделени ценности, способности, служители и стил (7S- модел на McKinsey), хора, формиращи комплекса от умения и нагласи в организацията (моделът ,звезда“ на Galbraith), управленска философия (конфигурациите на Miles\& Snow), неформална организация (модел 
на съответствието на Nadler\& Tushman), организационен климат и култура и лидерски стил (Burton\& Obel, 2004). „Есенцията““ на тези „меки“ компоненти са хората. От изградения „организационен софтуер“ в голяма степен зависи как ще работят „твърдите“ компоненти доколко добре ще се изпълняват отговорностите, колко пълноценно ще се анализира постъпилата чрез начертаните информационни потоци информация, дали решенията, които се вземат, ще са добри или не толкова добри, дали написаните правила ще се спазват или ще се заобикалят, дали системата за измерване на резултатите ще работи адекватно и ще съдейства за повишаването им или ще наблюдаваме поведение, което по- скоро манипулира резултатите.

Табл.1. Компоненти на организационния дизайн - съпоставка между моделите

\begin{tabular}{|c|c|c|c|c|c|c|}
\hline $\begin{array}{l}\text { компоненти } \\
\text { на модела }\end{array}$ & $\begin{array}{l}\text { 6- компонентен } \\
\text { модел, } \\
\text { Weisbord (1976) }\end{array}$ & $\begin{array}{c}\text { Моделът } \\
\text { „звезда““, } \\
\text { Galbraith (1973) }\end{array}$ & $\begin{array}{l}\text { 7S модел } \\
\text { McКinsey } \\
\text { (1977) }\end{array}$ & $\begin{array}{c}\text { Модел на } \\
\text { съответствието } \\
\text { Nadler \& Tushman } \\
(1980) \\
\end{array}$ & $\begin{array}{l}\text { Типология на } \\
\text { Miles \&Snow } \\
\quad(1994)\end{array}$ & $\begin{array}{c}\text { Аизайн модел } \\
\text { Burton \& Obel } \\
(2004)\end{array}$ \\
\hline среда & & & & $\begin{array}{c}\text { среда+ ресурси+ } \\
\text { история }\end{array}$ & & среда \\
\hline \multirow{5}{*}{$\begin{array}{c}\text { организационен } \\
\text { „хардуер“ }\end{array}$} & стратегия & стратегия & стратегия & стратегия & стратегия & стратегия \\
\hline & структура & структура & структура & \multirow{4}{*}{$\begin{array}{c}\text { формална } \\
\text { организация }\end{array}$} & структура & структура \\
\hline & възнаграждения & възнаграждения & \multirow{3}{*}{ системи } & & & \\
\hline & $\begin{array}{c}\text { полезни } \\
\text { механизми } \\
\end{array}$ & & & & & \\
\hline & & процеси & & & процеси & технология \\
\hline \multirow{4}{*}{$\begin{array}{c}\text { организационен } \\
\text { „софтуер“ }\end{array}$} & & xора & служители & индивиА & & \\
\hline & $\begin{array}{c}\text { взаимо- } \\
\text { отношения }\end{array}$ & & $\begin{array}{c}\text { споделени } \\
\text { ценности }\end{array}$ & \multirow{3}{*}{$\begin{array}{l}\text { неформална } \\
\text { организация }\end{array}$} & & $\begin{array}{c}\text { организационен } \\
\text { климат } \\
\end{array}$ \\
\hline & лидерство & & стил & & $\begin{array}{c}\text { управленска } \\
\text { философия }\end{array}$ & $\begin{array}{c}\text { управленски } \\
\text { стил }\end{array}$ \\
\hline & & умения & способности & & & \\
\hline
\end{tabular}

Организационният хардуер или компонентите, които се очаква да останат стабилни по- продължително време, задават, както метафорично ги нарича Gersick (1991), „дизайнът на игралното поле и правилата на играта“. Тези правила може да са по- рестриктивни или полиберални и с това да ограничават или да дават свобода на действие на играчите в игралното поле. От друга страна, наличието на стабилни, непроменящи се правила и игрално поле, не означава, че „всеки мач ще е еднакъв, или че резултатите ще остават постоянни“, обръща внимание Gersick (1991).

\section{3. Избор на дизайн: изисквания при избора с оглед постигане на адаптивност}

Стъпвайки на горната метафора и връщайки се към въпроса, който е във фокуса на нашето внимание, а именно „кои компоненти на дизайна имат по- значим принос за изграждане на способността на организацията да се адаптира“, можем да допуснем, че това, което ще направи организацията по- приспособима към променящи се условия, са качествата, уменията, отдадеността на участващите в играта, тяхната способност да мобилизират потенциала си при нововъзникнало предизвикателство, стилът на ръководителя им, екипността и степента, в която споделят едни и същи ценности - все елементи, които съставят съдържанието на „организационния софтуер“. В същото време, докато ресурсите се пренасочват при възникване на нова ситуация и играта сменя хода си, на играчите е необходима увереност, че „правилата на играта и дизайнът на игралното поле“ (организационният хардуер) са стабилни, запазват се същите и „опазват“ играта от това да излезе от контрол. Така при избора на организационен хардуер пред мениджърите стои задачата да изберат такива компоненти, които, в случай че средата е динамична и трудно 
предвидима, респ. изисква по- често адаптиране, да дават достатьчно свобода на действие при пренасочване на ресурсите и да позволяват навременна реакция.

Освен заради необходимостта от някакво ниво на сигурност в несигурната среда, стабилност в компонентите на дизайна е необходима и по друга причина: когато средата е динамична, приспособяването към нея не би могло да стане с непрекъснати промени в дизайна в отговор на променени обстоятелства - промените отнемат време и ако са извършвани често е много вероятно организацията да се окаже в позиция на „догонваща“ промените във външната среда. Така динамичната среда, вместо непрекъснати промени в дизайна, изисква по- скоро избор на такъв дизайн, който е адаптивен към променящата се среда. Консултанти от McKinsey \& Company посочват три ключови компонента на организационния дизайн, за които „балансирането на противоречието между стабилност и гъвкавост е критично: организационна структура, която определя как се разпределят ресурсите; ръководство, което задава правилата за вземане на решения; и процеси, които определят как се изпълняват дейностите, включително как се управлява и измерва изпълнението" (Aghina et al., 2016). На тези компоненти изследователите от McKinsey гледат като на "относително непроменящ се набор от основни компоненти“, който метафорично наричат „фиксирания гръбначен стълб“ на организацията (Aghina et al., 2016), този, който трябва да поддържа нейната стабилност. Сходни на тези елементи са включени като „организационен хардуер“ и в моделите за организационна диагностика и дизайн, показани по- горе в таблицата. Всички представени в нея модели разглеждат включените в тях компоненти и в тяхната взаимовръзка със стратегията на организацията - всички те трябва да подкрепят нейното изпълнение.

Какво придвижва организациите от една възможност към друга и ги прави адаптивни, осигурява навременен и адекватен отговор на промените в средата? Консултантите от McKinsey настояват, че наред с определянето на структурата, процесите и начина на вземане на решения (по- „твърдите“, фиксирани компоненти) “организациите трябва в същото време да създадат и по- хлабави, по- динамични елементи, които бързо да се адаптират към новите предизвикателства и възможности“ (Aghina et al., 2016). Те обръщат внимание, че "гъвкавите компании осъзнават, че стабилността на организационния дом (звеното в организационната структура, което остава постоянно за служителя - коментарът мой, В.М.) е критична, защото помага на организациите лесно и бързо да пренасочват служителите си към по- малко успешни звена, избягвайки стреса и страха от загуба на работното място, които традиционно възпрепятстват организационната промяна“ (Aghina et al., 2016). Търсейки кое отличава компаниите с превъзхождащи конкурентите им резултати от останалите фирми, McGrath (2012) по подобие заключава, че те са „едновременно изключително стабилни, с определени организационни характеристики, които остават едни и същи за дъльг период от време““ и „бързо настройват (приспособяват) и пренастройват ресурсите си и безпроблемно придвижват мениджъри и други служители от една роля към друга“. Тези чести промени в ролите, които служителите и мениджърите изпълняват, при това по- скоро без съпротива, формират и развиват комплекс от умения и възгледи у служителите, укрепват организационните връзки и доверието между служителите, интензифицират потока от информация и обмяната на знания.

Именно „информацията в широк контекст - по смисъла добиване на информация, скорост на обработка, информационен капацитет и др.“ Калинов (2017) добавя като „още един критерий за успешна адаптация“ и я нарежда сред „основните предпоставки за реализиране на адаптивността“. На „повишаващите се информационни изисквания“ на сьвременността, на които трябва да отговори организационното проектиране, обрьща внимание и М. Александрова (2003). Авторьт посочва, че организационното проектиране трябва „да обезпечи такъв тип движение на информационните потоци в хоризонтална и вертикална посока, за постигане както на стратегическите, така и на оперативните цели на организацията“" и подчертава ролята на хоризонталните комуникации за развитието на сьвременната „самообучаваща“ се организация. 
На основата на краткия преглед на аспектите, на които различни автори акцентират с оглед формиране на адаптивни организации, можем да очертаем някои важни характеристики на организационния дизайн, които биха направили организациите по- бързо реагиращи, а в по- добрия случай и проактивни, по отношение на предизвикателствата на средата. Така организационният дизайн следва да предполага и/ или позволява:

- сравнително бързо и с минимални сътресения прелокализиране на ресурсите, вкл. човешките, насьрчаване на инициативността на служителите;

- по- интензивна обмяна на знания и придобиване на нови такива в рамките на мултифункционални екипи, обединени около процес или задача;

- развитие на хоризонталните комуникации, намаляване на йерархичните равнища, формиране на самоуправляващи се екипи, което да съкрати времето за получаване и обработване на информацията и да улесни и ускори процеса на вземане на решения.

Сред организационните модели, коментирани в литературата по организационна теория, можем да откроим няколко, които в голяма степен покриват горните изисквания и появата им в практиката на организациите е предпоставена именно от търсенето на гъвкавост в поведението им в силно динамичната ни съвременност. Проектната структура и адхокрацията притежават от изброените по- горе характеристики и са призвани именно да осигуряват по- бърз отговор на изискванията на променящата се среда. Меритокрацията е сред изборите на мениджърите, когато наред с динамизма на средата е налице и високо ниво на технологичен прогрес (Birkinshaw and Ridderstråle, 2015). Възможностите на мрежовите структури да се напасват по- успешно към пазарните промени също са аргумент за избора им, когато средата изисква бързи реакции.

В основата на проектната структура стои именно идеята за временно прелокализиране на човешките ресурси към изпълнение на конкретна задача (проект), обикновено свързана с възникнала нова възможност. Проектното звено е съставено от специалисти от различните функционални отдели на фирмата в зависимост от потребностите при решаване на проектната задача. Последните продължават да са ангажирани с дейностите във функционалното звено, което им носи усещане за стабилност на работното място и прави по- спокойно и без съпротива пренасочването им и към друга дейност. Проектният екип действа автономно, като е ръководен от мениджър на проекта, подчинен директно на топмениджъра/ генералния мениджър. Това редуцира йерархичните равнища и ускорява процеса на вземане на решения. Различни функционални специалисти могат да бъдат привлечени в различни проектни екипи с различна продължителност на просъществуване на звеното в зависимост от срока на съответния проект. Така специалисти преминават от екип в екип в зависимост от потребностите в отделните проекти/ задачи. Това преминаване на квалифицирани кадри между различните екипи и „пренасяне“ на тяхното знание от задача в задача и от екип в екип е в основата на изграждане на самообучаващите се организации. Възникват нови свойства на организациите, които са в полза на тяхната адаптивност.

Адхокрацията като организационен модел обичайно се разглежда като антипод на бюрокрацията и като средство за по- бърз отговор на изискванията на променящата се среда чрез замяна на формалните правила и процедури с неформални механизми на взаимодействие в организацията. В статия, посветена на адхокрацията, Birkinshaw and Ridderstråle (2015) я разграничават не само от бюрокрацията, но и от меритокрацията като модел на организиране. Трите модела са разграничени според условията, при които са подходящи, което след това предполага и изисква различие и в начина, по който са координирани дейностите, начина, по който се вземат решенията и начина, по който хората биват мотивирани. И докато меритократичният модел е подходящ при високотехнологични дейности и интензивни технологични промени, то адхокрацията е във фокуса на вниманието при непредсказуемост на средата и силна несигурност.

Разчитайки на експеримента - опит за различен курс на действие, получаване на обратна връзка, реализиране на промени и преглед на напредъка, при адхок организациите 
служителите биват насърчавани да инициират нови проекти и да правят избори по кои от тях да работят. Екипите се сформират по- скоро спонтанно, обединени около нововъзникнала възможност. За разлика от екипите при проектната структура, които се създават с определен/ известен срок, при адхокрацията временните звена са с отворен срок - от няколко месеца до няколко години в зависимост от пазарния отзвук, който получи съответния проект. Мотивацията се търси чрез предоставяне на предизвикателства на служителите и осигуряване както на ресурсите, така и на свободата, които са им необходими за справяне с предизвикателството. Поведението на хората е мотивирано и от признанието, което ще получат при постигане на целите. Тук важна роля за по- безпроблемното въвличане на служители във временни екипи и осъществяване на промяната/ адаптацията играе принадлежността на служителите към някое от постоянните/ стабилните звена в структурата. В подкрепа на създаването на адхок структури е и ако мениджмънтът на организацията се ангажира след закриване на временното звено, хората, участвали в него, да бъдат насочвани и обучавани за включване в нововъзникващите възможности.

Трябва да се отбележи, че адхокрацията не може да е универсално решение за справяне с динамичността на средата - Birkinshaw and Ridderstråle (2015) съставят списък със ситуационни фактори, които повлияват уместността на адхокрацията. Така тя е подходяща при силна изменчивост на потребителските предпочитания и висока степен на неопределеност на средата, но само при условие, че възможността фирмата да повлиява в своя полза условията на средата също е висока и потребителските предпочитания са податливи на въздействие от нейна страна. За да е уместна адхокрацията, степента, в която от хората в съответния бизнес се изискват специализирани знания, за да работят ефективно, не трябва да е висока. При високи изисквания за специализирани знания по- подходяща е меритокрацията, поясняват изследователите (Birkinshaw and Ridderstråle, 2015). Подобно на проектните групи, в адхок екипите информацията протича по- бързо, знанията се обменят по- интензивно, насърчаването на инициативността прави по- лесно пренасочването на човешките ресурси между различните задачи и в резултат се повишава приспособимостта на организацията към промените в средата.

Когато обсъждаме вариантите на дизайн, които правят организациите поприспособими към средата като същевременно поддържат риска в умерени граници, интерес представляват и мрежовите организации. Те позволяват на организациите да растат, без това задължително да означава пропорционално нарастване на необходимостта от инвестиции във физически ресурси, увеличаване на бариерите за изход и намаляване или загуба на гъвкавостта. Като правило с нарастване на размера на организацията тя става по- тромава, често опасно нараства бюрократизирането, контрольт и координирането се усложняват, вземането на решения се забавя. Мрежовите организации са възможност компанията да действа като “голяма и малка едновременно" (Miles \& Snow, 1994). Запазвайки само тази част от процеса и от общата верига на стойността, в която „притежава отличителни компетенции и може да се конкурира на световно ниво“, компанията може да се смали, оставайки голяма, като прехвърли останалите дейности от веригата на субконтрактори, с които да изгради стабилни или динамични мрежи.

В допълнение на повишената гъвкавост, изграждането на мрежова организация ще позволи по- ефикасно изразходване на средства, освобождавайки организацията от разходи на време и пари за обслужване на бюрократичната машина. Бюрократичната контролна система (базирана на спазване на правила и процедури), преобладаваща в големите фирми, ще отстьпи място на контрол чрез пазара (Ouchi, 1980), където цените, предложени от субконтракторите предоставят „лесно“ мерило за ефективността.

Когато времето за реакция е критично за успеха, а инвестирането в скъпи и тясно специализирани активи е рисково поради чести и значими промени в технологиите и често променящи се потребителски предпочитания, Miles and Snow (1994) препоръчват при избора на организационен модел да се обмислят и т. нар. „динамични мрежи“. 


\section{4. Още някои отличителни черти на успешните фирми: емпирични резултати}

Всяка от разгледаните структури е повече или по- малко подходяща в зависимост от типа промени, които се случват в средата, големината на фирмата, степента на изисквани специфични за дейността знания или активи и т. н. Или, веднъж избран дизайнът на организацията, дори носейки характеристиките на такъв, който осигурява по- добра адаптивност на организацията, е необходимо периодично да бъде преразглеждан. При промяна в ситуационните променливи, може да е уместно някои елементи на дизайна да бъдат препроектирани. "Подвижните компании регулярно преосмислят и, ако е необходимо, препроектират своите структури, ръководни механизми и процеси, за да намерят баланса между скорост на реакциите и стабилност“, обрьщат внимание и Aghina, De Smet \& Weerda (2016) от McKinsey and Company.

За да преминава организацията през процеса на преосмислане на дизайна с по- малко проблеми и съпротива, характеристики като организационен климат, лидерски стил, изградени взаимоотношения между членовете на персонала, имат значение. "Критична предпоставка за поддържане на действителна промяна е установяването на поведенческите норми, необходими за постигането на успех“, предупреждават Aghina, et al. (2016) и обвързват успеха в редизайна със степента, в която поведенческите норми са възприети от членовете на организацията: “колкото по- ясни и широко възприети сред всички нива и звена на компанията са тези норми, толкова по- лесно ще е да се променят структурата, ръководните механизми и процесите, когато се стремим към гъвкавост“. В своя ситуационен модел за организационен дизайн наред със ситуационни променливи като размер на организацията, технология, среда и стратегия, Burton \& Obel (2004) включват и лидерския стил и организационния климат и култура. По подобен начин, нашето допускане е, че такива „меки“ характеристики на организациите играят важна роля за постигането на съответствие между „твърдите“ и по- „меки“ компоненти на цялостния дизайн, за адаптирането на организацията към промените в средата и, не на последно място - за осмисляне на необходимостта от редизайн.

В тази част обрыщаме внимание на няколко фирмени характеристики, които наше изследване сред български фирми показа, че корелират с успеха на фирмата и с поддържането на този успех. Изследването е сред фирми от млекопреработвателния бранш в България, който в периода на изследването се характеризира с множество предизвикателства от външната среда - проблеми в сектора на доставчиците, недостиг на суровина, недостиг на специализирани кадри и деквалификация на човешкия ресурс в сектора, високи разходи за дистрибуция и висока договорна сила на тьрговците, променящи се нормативни изисквания и слабости в контрола, отварящи път за нелоялна конкуренция. Всичко изброено оформя средата като динамична и поставяща на изпитание адаптивните способности на организациите в бранша. Изследването обхваща 40 организации, които формират около 1/5 от всички регистрирани към момента на провеждането му участници в бранша, като резултатите им са проследени за период от шест последователни години.

Емпиричните резултати свидетелстват за ролята на взаимоотношенията с контрагентите, лоялността на персонала, способността да се реализират иновации и прочие характеристики, в по- голямата си част от т. нар. „организационен софтуер“, за поддържането на устойчиви резултати на фона на агресивна среда. Последното е индикатор, който недвусмислено се свързва със способността на организациите да се адаптират и да намират подходящите и навременни решения, когато средата ги изправи пред предизвикателство. По- конкретно, резултатите от проучването показват, че за фирмите, които успяват да поддържат резултати над средните за отрасъла, е валидно, че:

- поставят фокус върху m. нар „ресурси, отразяващи взаимоотношения “ - при интервютата с мениджърите на фирмите, попаднали в извадката, те са попитани “Ако трябва да подобрите нещо в работата си, така че да запазите/ повишите успеха си в конкурентната надпревара, на какво бихте дали приоритет?“ Отговорите за ресурсите и действията, които 
мениджърите поставят на първо място в списъка си с приоритети след това са класифицирани в пет групи: „отразяващи взаимоотношения“, организационни, технологични, човешки и материални ресурси. Изследвана е връзката между поддържането на успеха на фирмите и вниманието им към отделните групи ресурси. Всички фирми, които извеждат като свой приоритет т. нар “ресурси, отразяващи взаимоотношения" като отношения с тьрговците на продукта, отношения с доставчици, доверие на потребителя, лоялност на потребителя, имидж, попадат в групата на фирмите, които бележат ръст на приходите от продажби, надминаващ средния за отрасъла за разглеждания 6- годишен период;

- освен че заявяват „ресурсите, отразяващи взаимоотношения“ за свой приоритет, отговори на други въпроси показват, че това тяхно разбиране намира израз в действително предприети от тях действия. Така например те поддържат стабилни взаимоотношения с партньори от веригата на доставяне на стойност - $65 \%$ от фирмите в извадката с резултати над средните за сектора имат добре развити взаимоотношения с партньорите си по веригата на доставките: или участват в съвместни проекти, или подкрепят финансово партньорите си посредством авансови плащания в периоди на техни затруднения;

- ориентирани са към и действително реализират иновации. Ориентацията към непрекъснато усъвършенстване е характерна за успешните фирми - 85\% от фирмите с високи резултати са правили иновации в продукта през годината предхождаща изследването, като при половината от тях, обновяването е дори по- интензивно (последното е в рамките на последните три месеца). Обновяването и усъвършенстването в организацията на работа показва още по- категорична връзка с добрите резултати - всички фирми с рентабилност над средната $(100 \%)$ са внедрили организационни промени през годината предхождаща изследването като при $71 \%$ от тази група респонденти промените са били в рамките на последните три месеца преди изследването;

- разбират необходимостта и реализират идеята за наличие на съответствие между изискванията на стратегията и системата за възнаграждения - при 53\% от фирмите, които превъзхождат по резултат своите конкуренти системата за възнаграждение е в съответствие/ подкрепя избраната стратегия, при $37 \%$ от тях е неутрална спрямо стратегията, а само $10 \%$ от фирмите с високи резултати ги постигат въпреки несъответствието между системата за възнаграждения и избраната конкурентна стратегия. За сравнение, при 80 \% от изоставащите фирми (с резултати под средните) системата за възнаграждения не е обвързана с избраната стратегия;

- посочват за свой приоритет човешките ресурси и се радват на лоялност om страна на персонала - сред тези, които фокусират върху човешките ресурси, отново наймного са тези с ръст над средния за отрасъла (57\% от фирмите, чийто приоритет са човешките ресурси, са именно фирми с ръст над средния за отрасъла). $82 \%$ от мениджърите на фирмите, които превъзхождат конкурентите си в резултатите, дават високи оценки за лоялността на персонала си. В действителност, при 76,5\% от тази група респонденти специалистите трайно се задържат на работа в съответната фирма - над 90\% от специалистите работят във фирмата повече от три години. За сравнение, само 20\% от мениджърите на изоставащите фирми дават висока оценка за лоялността на персонала си и в действителност по- малко от половината, $42,7 \%$ от изоставащите фирми, успяват да задържат ключовите си специалисти за повече от 3 години.

- Фирмите, които превъзхождат конкурентите си по резултати, се отличават и по управленското си разбиране за причините за успеха, респ. за евентуален неуспех. Мениджърите, включени в изследването, са попитани къде/ в какви области биха търсили причините за неуспех в случай че претърпят такъв. Категорично всички мениджъри на компаниите с резултати над средните биха търсили причината за евентуален неуспех в грешки, произтичащи от работата на организацията (вътрешни причини) като 68\% посочват единствено фактори на вътрешната среда като евентуална причина за неуспех. Останалите 
32\% биха търсили причините за неуспеха едновременно вътре във фирмата и в условията на външната среда. За сравнение, само $20 \%$ от изоставащите фирми биха търсили причините преимуществено вътре във фирмата. Повечето биха “обвинили” и външната среда за неуспеха си, а 10\% от тях отдават неуспеха си единствено на причини, идващи отвън. Считаме, че анализирането на причините за неуспеха само по себе си е в полза на организационното учене. Търсенето на причините вътре в организацията, от една страна означава, че процесите в нея биват подложени на обстойно анализиране и това подпомага ученето, а от друга страна - индикира за стремежа на организацията да се усъвършенства, откривайки и коригирайки грешките си.

Потвърждение за значимостта на част от изброените характеристики за адаптивността на организациите намираме и в резултати от емпирични изследвания на други автори. „Мениджмънт на персонала“ и „работа с доставчиците“ са сред характеристиките, които получават над средната оценка за значимост по отношение на адаптивността в изследване на Пенчев и Петков (2014) сред български организации. В статия на Bottani (2010) са докладвани резултати от по- широко проучване ${ }^{1}$, целящо да установи профила на адаптивните компании и средствата, чрез които постигат адаптивност. От общо 32 характеристики на адаптивността, включени в изследването, сред тези, които получават найвисоки оценки за значимост по отношение на адаптивността са „непрекъснати подобрения“ и „основани на доверие взаимоотношения с потребителите и доставчиците“.

Така значимостта на изведените от нас характеристики на организацията, описващи характера на взаимоотношенията с контрагентите, работата с персонала и лоялността му към фирмата, интензивността на иновациите, се валидира и от резултатите от други проучвания. В цитираните проучвания не се разглежда съответствието между стратегия и система за възнаграждения като фактор, влияещ на адаптивността. Управленското разбиране за причините за евентуален неуспех също е променлива, която не намираме като обект на разглеждане в цитираните изследвания. Считаме, че пригодената към стратегията система за възнаграждения, наред с фокуса върху човешките ресурси и лоялността на персонала, е в полза на мотивацията и е условие промените да се случват с по-малко съпротива и повече решимост. Управленската нагласа за учене от грешките ведно с разбирането за необходимостта от непрекъснато усъвършенстване и фокус върху иновациите превръща осъществяването на промени в по- скоро рутинна дейност, което е в полза на адаптивността.

\section{Заключение}

Развиването на характеристиките на адаптивността е от критично значение за успеха на всяка организация, особено когато средата е динамична и често непредсказуема. Важна задача на мениджмънта е изборът на такъв организационен дизайн, който да позволява на организацията да остане стабилна в преследването на целите си докато се променя в отговор на промените в средата.

Както елементите на организационния хардуер, така и по- меките характеристики на организацията са от значение, когато целта е да се постигне бързина при оползотворяване на нововъзникващи възможности и гъвкавост при преодоляване на проблемите. От проектирането на хардуера зависят границите, в рамките на които поведението на мениджърите и служителите може свободно да се променя. „Хардуерът на организацията“ е този, който ще ограничи или ще даде повече свобода за решенията и ще направи вземането на тези решения по- бавно или по- бързо. От „организационния софтуер“ зависи доколко

\footnotetext{
1 Проучването обхваща 190 компании. Сред тях попадат организации от сферата на здравеопазването, търговията, услугите, промишлеността и хранителната индустрия. В последната група (в каквато са и фирмите от нашето изследване) попадат $30.8 \%$ от респондентите в изследването на Bottani. Същевременно около $65 \%$ от респондентите в нейната извадка са малки и средни фирми, каквито са преобладаващо и фирмите, попаднали в нашата извадка.
} 
възможностите, които предоставя хардуера ще бъдат оползотворени. За част от характеристиките на софтуера получихме емпирично потвърждение в наше и в други изследвания, че влияят позитивно на адаптивността на организацията и на възможностите й да поддържа високи резултати в променяща се обстановка.

Разбира се списъкът с променливи, които биха направили една организация адаптивна може да бъде много по- дълъг. Считаме, че изведените в статията могат да са добра насока както за практикуващите мениджъри като очертават областите, които е необходимо да получат повече внимание, така и за бъдеща изследователска работа по разработване на по- детайлен профил на адаптивната организация.

\section{References}

1. Alexandrova, M. (2003) Contemporary tendencies of the design of organizational structures: issues and perspectives. Management and sustainable development, 8 (1-2), pp 218-221

2. Aghina, W., A. De Smet \& K. Weerda (2016) Agility: It rhymes with stability//in McKinsey On Organization: Agility and organization desigh, May 2016, McKinsey \& Company

3. Bernardes, E., M. Hanna (2009). A theoretical review of flexibility, agility and responsiveness in the operations management literature. International Journal of Operations \& Production Management Vol. 29 No. 1, 30-53

4. Birkinshaw, J., J. Ridderstråle (2015) Adhocracy for an agile age//McKinsey Quaterly, December 2015, McKinsey \& Company

5. Bottani, E. (2010). Profile and enablers of agile companies: An empirical investigation. International Journal of Production Economics, vol. 125, 251-261

6. Boylan, S., K.Turner (2017) Developing Organizational Adaptability for Complex Environment. Journal of Leadership Education, vol.16( 2), pp 183-198

7. Burton, R., Obel, B. (2004) Strategic Organizational Diagnosis and Design: The Dynamics of Fit, Dordrecht, Kluwer Academic Publishers

8. Galbraith, J. (1973). Designing complex organizations. Reading MA: Addison-Wesley

9. Gersick, C. J. (1991). Revolutionary Change Theories: A Multilevel Exploration of the Punctuated Equilibrium Paradigm. The Academy of Management Review, 16(1), 10-36

10. Greenwood, R., D. Miller, (2010) Tackling Design Anew: Getting Back to the Heart of Organizational Theory. Academy of Management Perspectives, Vol. 24 (4), p.78-88.

11. Greiner, L.E. (1972) Evolution and Revolution as Organizations Grow, Harvard Business Review, July-August 1972, pp 37-46

12. Kalinov, K. (2017) Aspekti na teoriyata na organizatsiite, Dangrafik, Varna

13. McGrath, R. (2012). How the Growth Outliers Do It. Harvard Business Review, Jan-Feb 2012 https://hbr.org/2012/01/how-the-growth-outliers-do-it

14. Miles, R. E., C.C. Snow (1994) Fit, failure, and the hall of fame: how companies succeed or fail. New York, The Free Press

15. Nadler, D., M. Tushman (1980). A Model for Diagnosing Organizational Behavior. // Organizational Dynamics, Vol. 9 (2), pp. $35-51$

16. Ouchi, W. (1980) Markets, Bureaucracies, and Clans. Administrative Science Quarterly, vol. 25(1), pp 129-141

17. Penchev, P., A. Petkov (2014) Rezultati ot pilotno izsledvane na hipotezata za adaptivnoto predpriyatie v usloviyata na Balgariya. Universitetski izdateslki tsentar. RU "Angel Kanchev", Ruse

18. Weisbord, M.R. (1976) Diagnosing your organization: Six places to look for trouble with or without theory. Group and Organization Studies, vol. 1, pp. $430-447$. 